\title{
A study mimicking fungus and lichen mechanisms to achieve thermal comfort in buildings
}

\author{
S. E. Selim \& H. Taleb \\ British University in Dubai, UAE
}

\begin{abstract}
Biomimicry is simply being inspired by nature, making maximum use of its intensive research into what works and what is appropriate for this planet's various environments. Mimicking nature can be inspired by strategies, structures or even adaptation techniques. The aim of this research is to investigate and understand how fungus and lichens adapt to harsh environments in which they can be found and apply these techniques to a human living space, optimising the consumed energy while trying to achieve visual and thermal comfort. A typical residential villa in Dubai was chosen as a case study. With the help of climatic simulation software, an improvement in visual and thermal comfort levels was detected as well as energy saving after applying the mimicked techniques. Moreover, the paper introduces some nature-inspired techniques and recommendations that should be implemented in these particular climatic conditions, which will help achieve indoor visual and thermal comfort, as well as decrease energy consumed to do so. As a final note, although this paper is mainly focused on a UAE-based building, it could be argued that the research outcomes are relevant to several countries, especially those with similar climatic conditions.
\end{abstract}

Keywords: biomimicry, thermal behaviour, visual comfort, UAE, Ecotect.

\section{Introduction}

Biomimicry is simply being inspired by nature. As a knowledge source, nature has been dedicated to research for 3.8 billion years, investigating solutions, trying, enhancing, developing and adapting to the environment. Therefore, nature has all the answers we need because it knows what works and what is 
appropriate for our environment and for sustaining life on this planet [1]. Throughout history, architects have been nature-inspired starting from building form all the way through to decoration, this project is aiming to study a very particular aspect of nature - in fact it is on a micro-scale of sustainability and bio-inspired architecture. The study will be investigating and extracting sustainable strategies from fungi and lichens in order to help create a living space that can provide comfort. Comfort on its own is broadly defined, so a couple of forms of comfort have been highlighted; namely visual and thermal comfort. The study was conducted through experimental approaches utilizing a case study located in Sharjah, UAE. It was selected to be fully analyzed using climatic simulation software in both its currently existing status and after bio-mimicking the fungal and lichen strategies and techniques. This means conducting a comparative study between both analyses and highlighting visual and thermal enhancements that occur within the case study.

\section{Literature review}

The term 'biomimicry' appeared as early as 1982 and was popularized by a scientist and author in the 2002 book Biomimicry: Innovation Inspired by Nature. Biomimicry is defined in her book as a "new science that studies nature's models and then imitates or takes inspiration from these designs and processes to solve human problems" [2]. Benyus suggests looking to nature as a "model, measure and mentor" and emphasizes sustainability as an objective of Biomimicry.

Architects and designers have looked to biology for inspiration since the beginnings of science in the early nineteenth century. They have sought not simply to imitate the forms of plants and animals, but also to find methods in design analogous to the processes of growth and evolution in nature. Biological ideas are prominent in the writings of many modern architects, of whom Le Corbusier and Frank Lloyd Wright are the most famous. Le Corbusier declared biology to be the 'great new word in architecture and planning'. Although there is much that is completely new in recent biological developments in the practice and theory of design, this work does nevertheless often tend to echo or reinterpret ideas in the earlier history of biological analogy. Modern research in biomimetics (an engineering analysis of organisms and their behavior with a view to applying the same principles in design) gives a new name and new rigour to what went under the banner of 'biotechnique' or 'biotechnics' in the 1920s and 1930s.

\section{Methodology}

This study will investigate and extract sustainable strategies from fungi and lichens in order to create a living environment that can provide comfort. Comfort is a broadly definition, so this project specifies thermal comfort as the target. Research was conducted using an experimental approach through a case study located in Sharjah, UAE - that was selected by fixing location, climate and 
orientation variables. The selected case study will be fully analyzed using climate simulation software (Ecotect) in both its currently existing status and after biomimicking some of the fungal and lichen strategies and techniques. A comparative study will be made of both analysis results and conclude on any thermal enhancements that occur in the case study.

\section{Case study}

The aim of this project is to enhance human comfort on a thermal level in a residential villa located in Sharjah, in the UAE.

\subsection{Location and orientation}

The case study is located in Sharjah, UAE and has a southeast orientation.

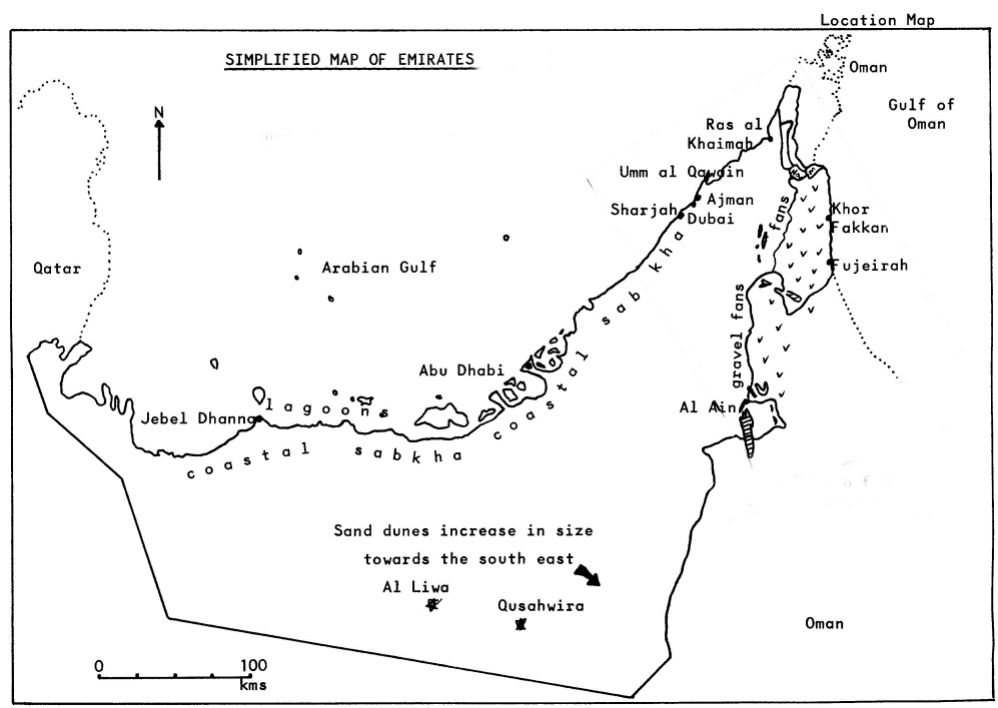

Figure 1: United Arab Emirates map showing the Emirate of Sharjah [3].

\subsection{Location climatic data}

Located in a harsh desert environment stretching between the Arabian Gulf and the Arabian Sea, Sharjah - as with all desert climates - has warm winters and extremely hot summers, rainfall is in expected in winter, precautions have to be taken as occasionally it pours heavily. According to the wind frequency diagram extracted from weather files using the Ecotect software, the favored wind is variable between the north and northwest with a strongest effect of between $10 \mathrm{~km} / \mathrm{h}$ to $20 \mathrm{~km} / \mathrm{h}$ from a northwesterly direction. While humidity levels are relatively high in summer, cloud cover is very variable across the year and most likely in winter. It sees a peak temperature of up to 47 Celsius in August and a 
direct solar radiation peak of $0.6 \mathrm{kw} / \mathrm{m}^{2}$ in November. The highest recorded direct solar radiation levels are $0.9 \mathrm{kw} / \mathrm{m}^{2}$ in December at noon.

\section{Case study existing conditions analysis}

To obtain credible results, the strategic assessment methodology is to conduct a comparative analysis by analysing the performance of the case study both before and after applying each strategy.

\subsection{Passive heat gains and losses (Ecotect)}

\subsubsection{Solar gain}

This is the increase of temperature in a space due to the absorption of solar radiation whether directly or indirectly. Before applying any strategies the solar heat gain due to direct radiations peak varied between 20000 Watts to 23000 Watts per month in summer and 12000 Watts to 18000 watts per month in winter.

\subsubsection{Fabric heat gains}

In the Ecotect software, fabric heat gain means the amount of heat gained or lost through the fabric of the building (walls, window or roofs, etc.). In this case, heat gained through the building fabric was between 14000 Watts per month and 17000 watts.

\subsubsection{Summary}

There was total peak heat gain of almost $1300 \mathrm{Wh} / \mathrm{m}^{2}$ in July gained through conduction, direct solar, indirect solar and ventilation. It was noticeable that direct solar gain is the most effective with $36.1 \%$ of the total heat gained by the case study's fabric (as shown in Figure 4).

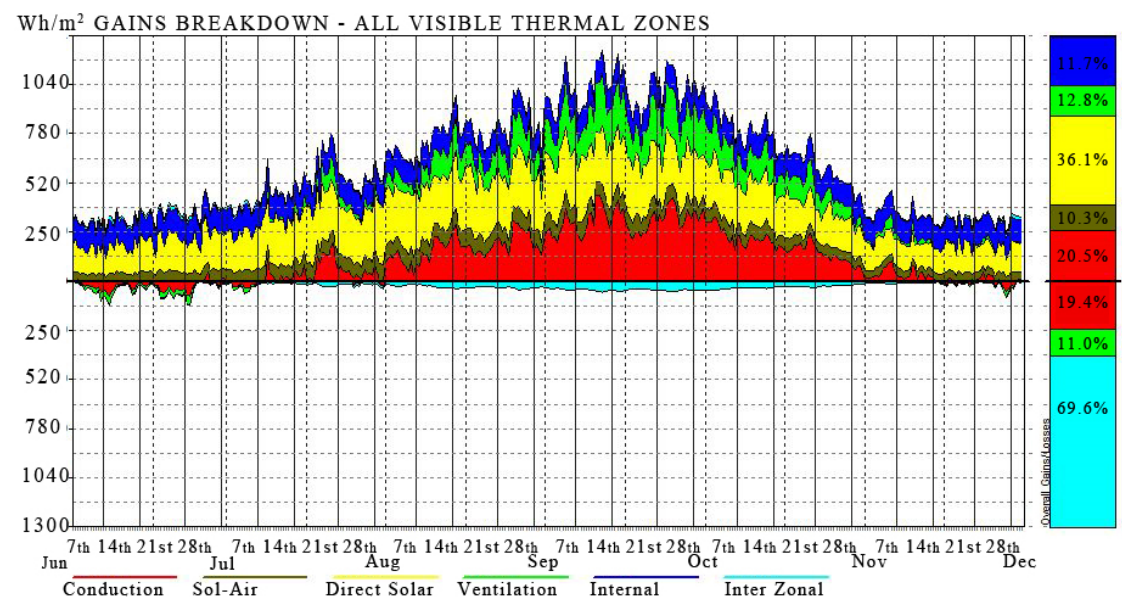

Figure 2: Passive heat gains breakdown (existing conditions) (source: Ecotect). 


\section{Biological approaches (fungus and lichens)}

\subsection{Symbiosis}

The main body of a fungus (mycelium) is made up of a dense network of thread like structures called 'hyphae' that look like plant roots and are how fungi takes in their food.[4]

Working on its own is not enough to extract all the nutrition that they need, so some of team up with plants and in some cases neither can survive without this relationship. This interaction is known as symbiosis; the plant swaps some of the carbohydrates collected by photosynthesis in return for minerals collected by the fungi from the soil [5].

\subsection{Lichens}

The species to be investigated is lichen, which is considered to be one of the oldest living things and is produced thanks to symbiosis between fungi and algae [6]. Lichens consist of an algal body attached to fungal filaments (hyphae). Figure 3 shows the agreement of mutual benefit - algae generate energy while the hyphae holds the algae, protects it and supplies minerals.

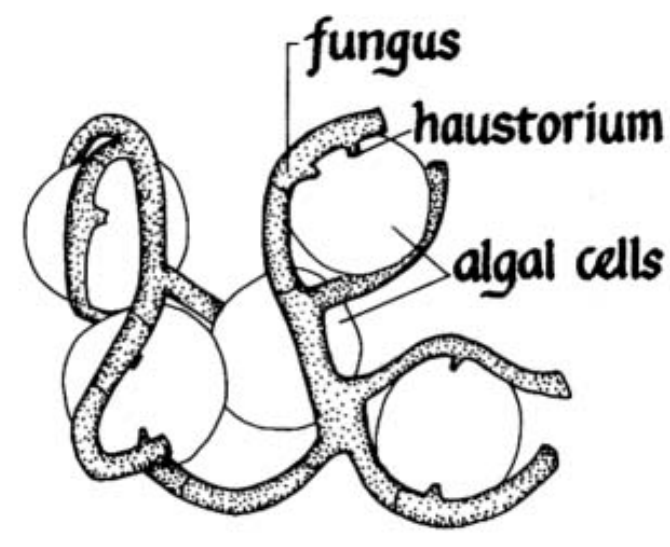

Figure 3: Illustration of fungal body holding algal cells and symbiosis (Yosemite [7]).

\section{Strategies}

\subsection{Strategy 1}

The first strategy is all about mutual benefit as the building outer walls will provide an additional structure (layer) or skin which can carry vegetation. The vegetation will be swapped for solar radiation and thermal screening linked to the building's supply structure and watering. This way the building will supply 
PVs with a structure to hold it and the PV will give back two things; the first being electricity (energy) and the second is heat generating an air flow which will decrease the building walls thermal content through convection. The final form of the idea is to use a double skin façade like a structure (green wall section) and apply the PV panels to the second skin.

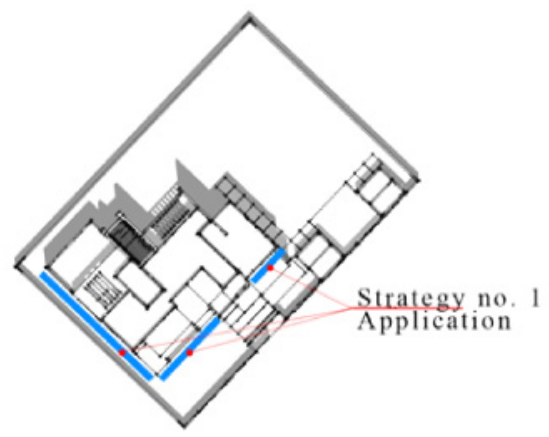

Figure 4: $\quad$ Strategy 1 development phase 4 (source: authors).

\subsection{Analysis of case study after applying strategy 1}

Using Ecotect, heat gain analysis has been conducted showing the effect of applying Strategy 1 on enhancing the thermal comfort of the case study.

\subsubsection{Direct solar gain}

Direct solar gain after applying strategy 1; in the summer months direct solar gain values reached a peak of 7000 Watts per month, decreasing from 23000 Watts per month in the summer before applying the strategy, which is a $69.5 \%$ decrease in direct solar gain at peak.

\subsubsection{Indirect solar gain}

indirect solar gain after applying strategy 1; in the summer months the indirect solar gain values were between 2000 Watts per month and 2700 Watts per month, decreasing from 4000 Watts per month to 4600 Watts per month, an average of $41.3 \%$ at peak.

\subsubsection{Fabric gain}

Fabric solar gain figures after applying strategy 1 are between 6000 watts per month and 11100 watt per month, a decrease from 14000 watts per month and 17000 , with an average decrease of $34.7 \%$ of peak fabric solar radiation gains.

\subsubsection{Summary}

Passive heat gains affecting the case study with percentages and values concluding in a total peak heat gain of almost $810 \mathrm{Wh} / \mathrm{m}^{2}$ after applying strategy 1 , dropping from a peak figure of $1300 \mathrm{Wh} / \mathrm{m}^{2}$ a $37.6 \%$ reduction. It is noticeable that direct solar gain is the most affected, decreasing from $36.1 \%$ of the total heat gained on the existing conditions analysis to only $14.2 \%$ of the total heat gained after applying the strategy. 


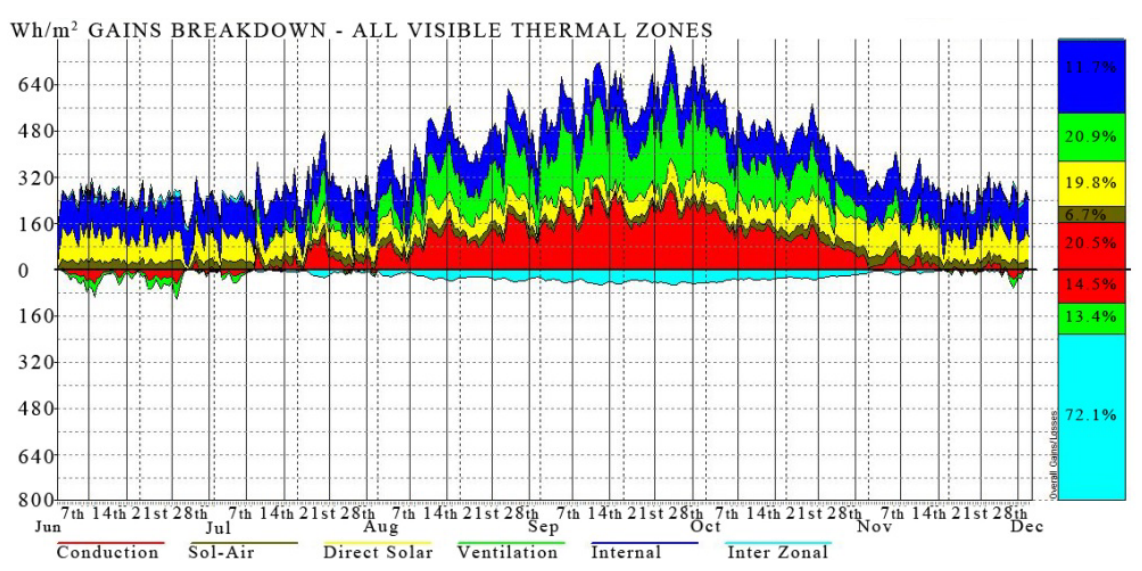

Figure 5: Passive heat gain (after applying strategy 1) (source: Ecotect).

\subsection{Strategy 2}

From analysis of the symbiosis process, it was observed that fungi provide algae with protection from UV rays and from dehydration with a complex thread like a fabric of fungal body on top of the algae that helps the algae maintain hydration and protects it from harmful radiation. This structure is very similar to tent fabric or textiles and this is how the second strategy was derived; covering the building and outdoor area that will be exposed to direct radiation (south and southwest) with tent-like structure.

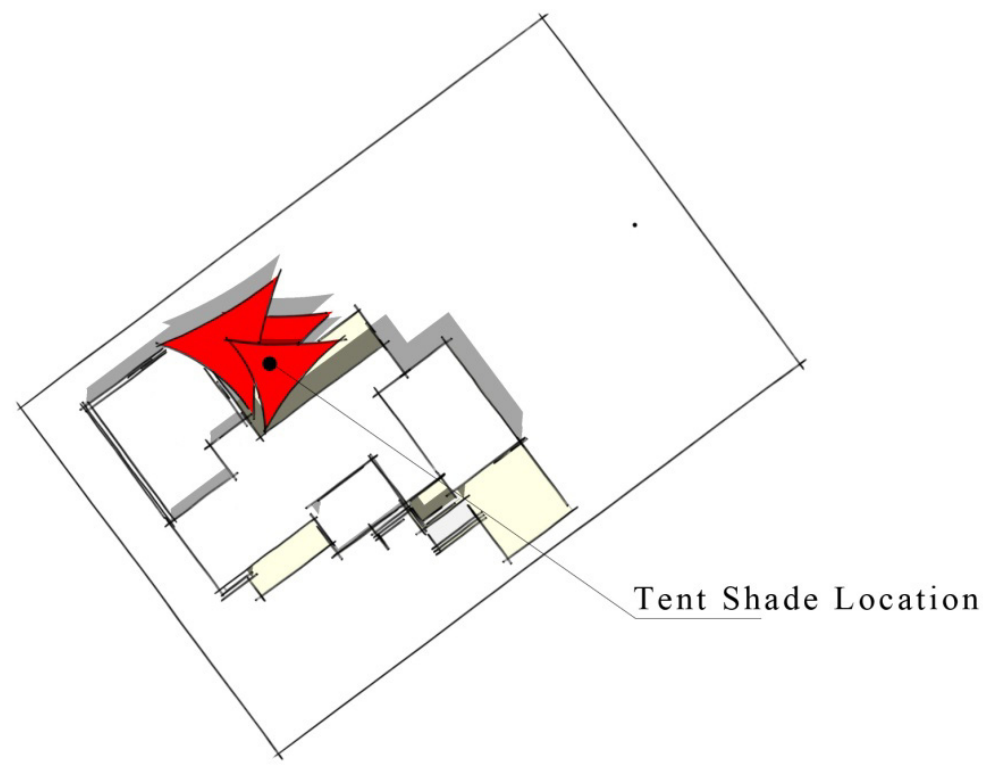

Figure 6: Location of tent-like structure to be fixed on the back yard of the case study villa (author). 
Studying the mushroom's anatomy the way it releases and spreads it spores (reproduction cells) from its gills can be seen. This in turn controls the speed and direction of the wind so that it can carry the spores away rather than them sticking back on the gills. This is where an enhancement sub-strategy came into consideration, as the tent-like structure will provide shading and can be oriented as to collect the favored wind coming from the north and northwest (wind catcher) feeding the shaded outdoor area with a mild breeze, also work on repelling unwanted wind away from the back yard.

\subsection{Analysis of case study after applying strategy 2}

\subsubsection{Direct solar gain}

Shown in Figure 7, the direct solar gain after applying strategy 2. In the summer months direct solar gain values are between to 6200 Watts per month peak, a decrease from 7000 Watts at peak values in summer before applying the strategy, which is an $11 \%$ additional decrease to that provided by strategy 1 .

\subsubsection{Indirect solar gain}

Indirect solar gain after applying strategy 2, in the summer months the indirect solar gain peak value was 2200 Watts per month, a decreased from 2700 Watts per month with an average $18.5 \%$ additional decrease to that provided by strategy 1 relating to direct solar gain at its peak value.

\subsubsection{Fabric gain}

Fabric solar gain figures after applying strategy 2, the peak value was 10000 watts per month, decreasing from 11000 Watts per month, with an average $9 \%$ additional decrease.

\subsubsection{Summary}

Passive heat gains affecting the case study in terms of percentages and values saw a total peak heat gain of almost $700 \mathrm{Wh} / \mathrm{m}^{2}$ after applying strategy dropping from a peak figure of $810 \mathrm{Wh} / \mathrm{m}^{2}$ after applying strategy 1 , increasing the total reduction of heat gain by another $11 \%$.
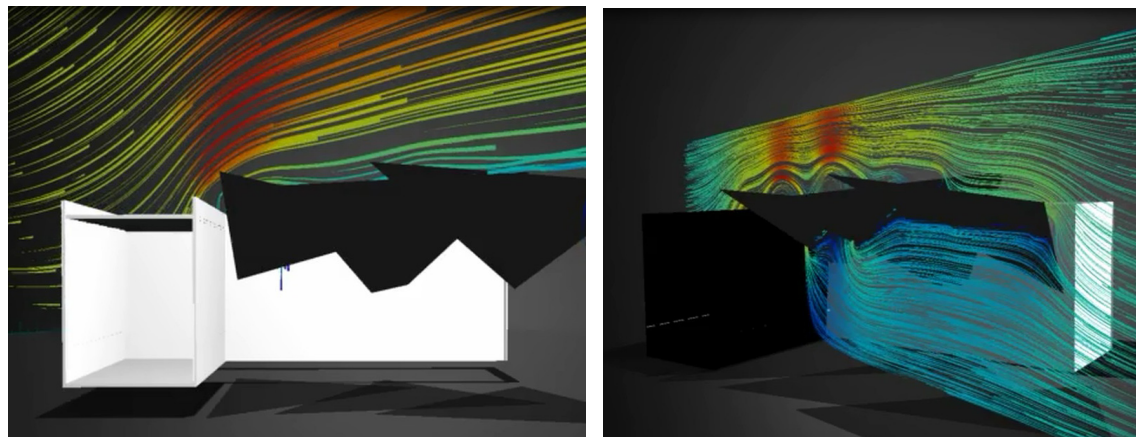

Figure 7: CFD analysis of tent-like shading against favoured and unwanted wind (source: Flow design). 


\section{Conclusion}

Throughout this paper we have looked at several strategies aiming to enhance human comfort inspired by mimicking the adaptation techniques of both fungi and lichen.

The total reduction of passive heat gains by the mimicking fungi and lichen strategies is around $48 \%$ of original heat gains in existing conditions, in addition to $52700 \mathrm{kwh} / \mathrm{yr}$ of electricity and the advantage of harnessing only the favored wind in the backyard of the case study, achieving the goal of enhancing the thermal comfort of the residential villa that was the case study of this project.

\section{Acknowledgement}

The authors would like to thank "MUSTADAMA Ltd. Sustainable Solutions" in Masdar City-Abu Dhabi for sponsoring this paper to be presented in the "Sustainable Development and Planning Conference" held in Istanbul in May 2015.

\section{References}

[1] Pawlyn, M., Biomimicry in Architecture, Riba Publishing: London, 2011.

[2] Benyus, J., (Second ed.), Biomimicry Innovation Inspired By Nature, HarperCollins Publishers Inc.: New York, 2002.

[3] Emirates Natural History Group (ENHG), http://www.enhg.org/

[4] Viegas, J., Fungi and Molds, The Rosen Publishing Group, Inc.: USA, 2004.

[5] Paola, B., G. A., (Tenth ed.), Nature Communications 1 (Chapter 10), Mechanisms underlying beneficial plant-fungus interactions in mycorrhizal symbiosis, pp. 1036-1046, 2010.

[6] Nash, T. H., Lichen Biology, Cambridge University Press: Cambridge, 2001.

[7] Yosemite. (Yosemite Online Library), http://www.yosemite.ca.us/library/

[8] Steadman, P., (revised ed.), The Evolution of Designs Biological analogy in architecture and the applied arts, Routledge: Oxon, 2008.

[9] Planning Department, Affection Plan, Sharjah Government: Sharjah UAE, 2012. 